\title{
Roscovitine sensitizes breast cancer cells to TRAIL- induced apoptosis through a pleiotropic mechanism
}

Gustavo Ortiz-Ferrón ${ }^{1}$, Rosario Yerbes ${ }^{1}$, Adriana Eramo², Ana I López-Pérez ${ }^{1}$, Ruggero De Maria ${ }^{2}$, Abelardo López-Rivas ${ }^{1}$

${ }^{I}$ Centro Andaluz de Biología Molecular y Medicina Regenerativa, Consejo Superior de Investigaciones Cientificas (CSIC), Avda Américo Vespucio s/n, 41092 Sevilla, Spain; ${ }^{2}$ Department of Hematology, Oncology and Molecular Medicine, Istituto Superiore di Sanità, Rome, Italy

The tumor necrosis factor (TNF)-related apoptosis-inducing ligand (TRAIL/APO2L) is a member of the TNF gene superfamily that induces apoptosis upon engagement of cognate death receptors. While TRAIL is relatively non-toxic to normal cells, it selectively induces apoptosis in many transformed cells. Nevertheless, breast tumor cells are particularly resistant to the effects of TRAIL. Here we report that, in combination with the cyclin-dependent kinase inhibitor roscovitine, exposure to TRAIL induced marked apoptosis in the majority of TRAIL-resistant breast cancer cell lines examined. Roscovitine facilitated TRAIL death-inducing signaling complex formation and the activation of caspase-8. The $_{\text {CFLIP }}$ and CFLIP $_{S}$ FLICE-inhibitory proteins were significantly down-regulated following exposure to roscovitine and, indeed, the knockdown of cFLIP isoforms by siRNA sensitized breast tumor cells to TRAIL-induced apoptosis. In addition, we demonstrate that roscovitine strongly suppressed Mcl-1 expression and up-regulated E2F1 protein levels in breast tumor cells. Significantly, the silencing of Mcl-1 by siRNA sensitized breast tumor cells to TRAIL-induced apoptosis. Furthermore, the knockdown of E2F1 protein by siRNA reduced the sensitizing effect of roscovitine in TRAIL-induced apoptosis. In summary, our results reveal a pleitropic mechanism for the pro-apoptotic influence of roscovitine, highlighting its potential as an antitumor agent in breast cancer in combination with TRAIL.

Keywords: apoptosis, roscovitine, CDK, TRAIL, DISC, FLIP, Mcl-1, E2F1

Cell Research (2008) 18:664-676. doi: 10.1038/cr.2008.54; published online 6 May 2008

\section{Introduction}

The tumor necrosis factor (TNF)-related apoptosisinducing ligand (TRAIL/APO-2L), a member of the TNF gene superfamily, induces apoptosis upon binding to the death domain (DD)-containing receptors TRAIL-R1/DR4 and TRAIL-R2/DR5 [1]. However, TRAIL can also bind to the decoy receptors TRAIL-R3/DcR1 and TRAIL-R4/ DcR2, which do not transduce apoptotic signals [2]. Since

Correspondence: Abelardo López-Rivas

Tel: +34-95-446-7997; Fax: +34-95-446-1664

E-mail: abelardo.lopez@cabimer.es

Received 17 October 2007; revised 3 December 2007; accepted 11 December 2007; published online 6 May 2008

Abbreviations: tumor necrosis factor-related apoptosis-inducing ligand (TRAIL); tumor necrosis factor (TNF); death-inducing signaling complex (DISC); Fas-associated death domain (FADD); cyclin-dependent kinase (CDK); FLICE-inhibitory protein (FLIP); benzyloxycarbonyl-Val-Ala-Asp(OMe) fluoromethyl ketone (z-VAD.FMK); poly (ADP-ribose) polymerase (PARP)
TRAIL induces apoptosis selectively in transformed cells of diverse origin but not in most normal cells in vitro, it is an attractive candidate for antitumor therapies [2-4]. However, some cancer cells show either partial or complete resistance to the apoptotic effects of TRAIL [3], although it appears that in certain instances this resistance can be overcome by combining TRAIL with chemotherapeutic drugs [5-7].

In the western world, breast cancer is the most common neoplasia amongst women, emphasizing the importance of developing effective treatments. Recently, different combined strategies have been studied to improve the effects of chemo- and radiotherapy. Indeed, we and others have reported that interferon-gamma, DNA-damaging drugs and ionizing radiation can sensitize breast cancer cells to TRAIL-induced apoptosis [8-10].

Upon binding to its proapoptotic receptors TRAIL induces the formation of the death-inducing signaling complex (DISC), recruiting the dual adaptor Fas-associated death domain (FADD) molecule through its DD. In turn, this complex recruits the initiator caspase- 8 through 
its death effector domain (DED) [11], which is activated at the DISC by oligomerization. The processing and activation of caspase- 8 at the DISC stimulates an apoptotic cascade that provokes cell death. The apoptotic signal from the DISC may be inhibited by the cellular FLICE-inhibitory protein (FLIP) [12]. In most cells, two alternatively spliced isoforms of cFLIP exist: a caspase- 8 homologue $\mathrm{cFLIP}_{\mathrm{L}}$ that lacks the amino acids critical for proteolytic caspase activity; and $\mathrm{cFLIP}_{\mathrm{S}}$, which is comprised of the two death effector domains alone [12]. Although the role of cFLIP in apoptotic signaling remains controversial, there is strong evidence that it displays antiapoptotic activity [13-15]. The expression of cFLIP varies in a cell type-specific manner and it fluctuates in response to various stimuli. While it can be transcriptionally controlled by the nuclear factor$\kappa \mathrm{B}(\mathrm{NF}-\kappa \mathrm{B})$ pathway [16], altered rates of proteasomal degradation also regulate its protein activity [17], making it a versatile inhibitor of the apoptotic responses mediated by death receptors.

Cyclin-dependent kinases (CDKs) are serine/threonine kinases that play a crucial role in regulating both the cell cycle and transcription, through the phosphorylation of transcription factors and tumor suppressor proteins involved in DNA replication and cell division [18]. Therefore, CDKs are attractive therapeutic targets for cancer therapy. Roscovitine (CYC202, Seliciclib) is a purine analogue that competes with ATP for binding to the active site of CDKs and it displays a potent in vitro activity against CDK1, CDK2, CDK5, CDK7 and CDK9 [19]. The growth of a wide range of tumor cell types is inhibited by roscovitine in vitro and, likewise, it inhibits the growth of human tumor xenografts in nude mice [20,21]. Roscovitine causes not only cell cycle arrest but also apoptosis in cancer cells [22] and, accordingly, it is currently being evaluated in phase II clinical trials [23].

While the mechanism by which CDK inhibitors induce apoptosis remains unclear, the CDK inhibitor flavopiridol, a semisynthetic flavone, reduces the levels of antiapoptotic proteins such as XIAP, Mcl-1 or cFLIP [24-26] and up-regulates the transcription factor E2F1, known to be involved in apoptosis [27]. Roscovitine may also downregulate Mcl-1 or XIAP [28] and it could sensitize glioma cells to TRAIL-induced apoptosis by reducing the levels of survivin and XIAP. However, the down-regulation of these factors may not be sufficient to trigger the activation of caspases [6].

Here we report that TRAIL-resistant human breast cancer cell lines can be sensitized to TRAIL-induced apoptosis by exposure to roscovitine. The molecular mechanisms underlying the effects of roscovitine involve an increase in the formation of the TRAIL DISC, the down-regulation of cFLIP and Mcl-1, and the up-regulation of the transcrip- tion factor E2F1.

\section{Results}

Roscovitine sensitizes human breast tumor cell lines to TRAIL-induced apoptosis

To analyze whether roscovitine sensitizes breast tumor cells to the apoptotic ligand TRAIL, the breast tumor cell line MDA-MB231 was treated with different concentrations of roscovitine to determine the sub-toxic dose capable of sensitizing them to TRAIL-induced apoptosis (Figure 1A). Subsequently, six more breast tumor cell lines were tested to determine whether similar doses also induced roscovitine sensitization to TRAIL-induced apoptosis (Figure 1B). In all the cell lines tested, roscovitine alone induced little cell death at the concentration indicated. However, if the cells were exposed to roscovitine for $7 \mathrm{~h}$ before adding TRAIL overnight, apoptotic cell death was significantly increased in all the cell lines tested, even in the highly resistant BT474 and SKBr3 cell lines that over-express the ErbB2/Her-2/neu oncogene. Proteolytic processing of the caspase substrate poly (ADP-ribose) polymerase (PARP), a hallmark of apoptosis, was observed in the cells treated with roscovitine and TRAIL (Figure 2A). These results demonstrate that the combined treatment with roscovitine and TRAIL induces significant apoptotic cell death in these breast tumor cell lines.

Roscovitine enhances TRAIL-induced activation of caspase-8 without affecting the cell surface expression of TRAIL receptors

To elucidate the mechanism underlying the sensitization to TRAIL-induced apoptosis promoted by roscovitine in breast tumor cells, we examined different biochemical events that occur upon TRAIL binding to its receptors at the cell surface. TRAIL initiates apoptosis by inducing the recruitment of the adapter molecule FADD to the apoptotic TRAIL receptors and the subsequent engagement and activation of procaspase- $8[29,30]$. We determined whether caspase- 8 was activated in MDA-MB231 cells by analyzing the processing of the pro-caspase to the $43 / 41$ $\mathrm{kDa}$ intermediate proteolytic fragments, and through the generation of the mature 18 caspase- 8 subunits upon TRAIL stimulation. Accordingly, TRAIL-induced activation of caspase- 8 was clearly enhanced by pre-treatment with roscovitine (Figure 2A).

Several treatments have been shown to up-regulate the expression of the TRAILR1 (DR4) or TRAILR2 (DR5) death receptors, resulting in enhanced TRAIL-induced apoptosis [31]. We therefore examined the effect of roscovitine on the surface expression of TRAIL death and decoy receptors by flow cytometry (Supplementary information, 
A

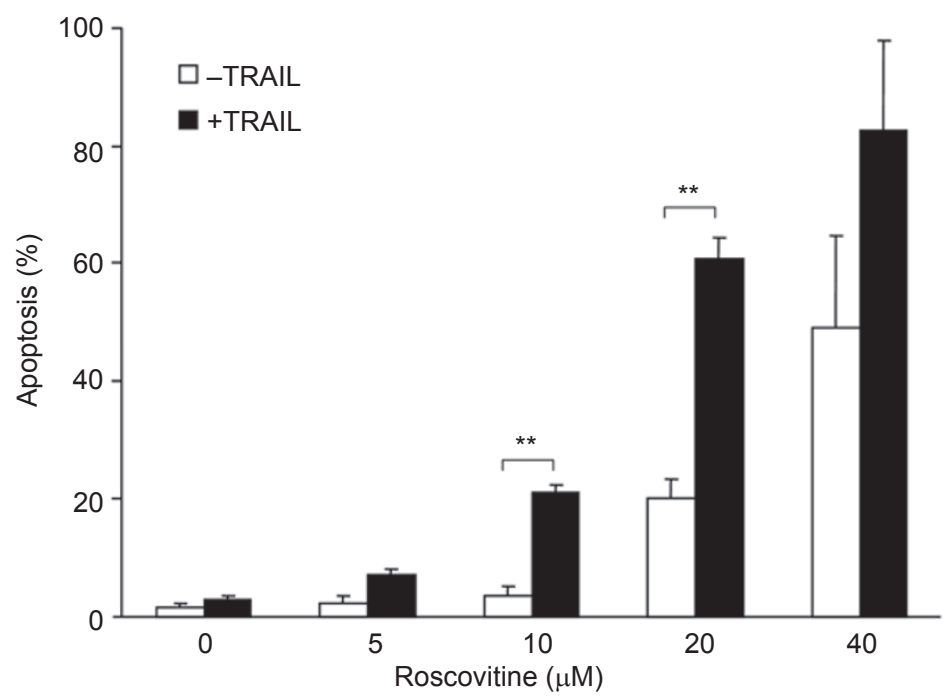

B

$\square$ Control
$\mathbb{Q}$ Roscovitine
$\square$ TRAIL
$\square$ Roscovitine + TRAIL
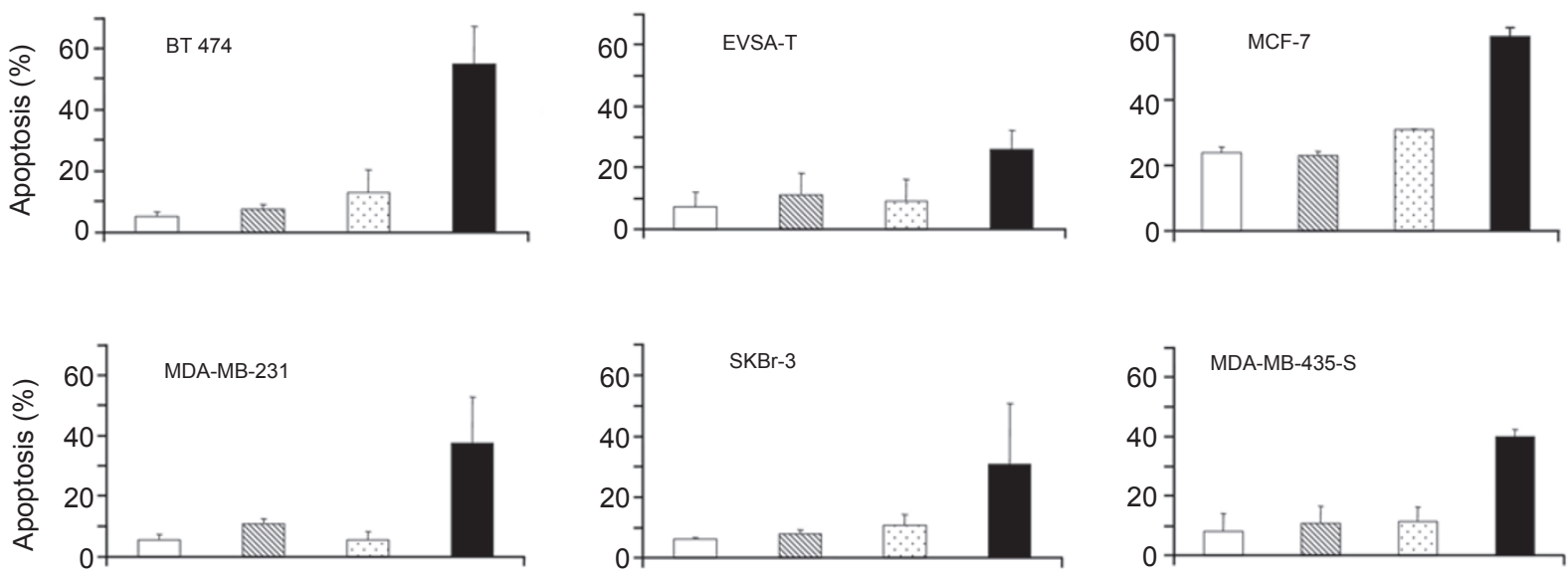

Figure 1 Roscovitine sensitizes breast tumor cell lines to TRAIL-induced apoptosis. (A) MDA-MB231 cells were incubated with the indicated concentrations of roscovitine for $7 \mathrm{~h}$ prior to the addition of TRAIL. Apoptosis was measured $15 \mathrm{~h}$ after the addition of TRAIL $(500 \mathrm{ng} / \mathrm{ml})$ as the percentage of cells with sub-G1 DNA content, as described in Materials and Methods. Error bars represent S.D. from three independent experiments. ${ }^{* *} P<0.0001$. (B) Different breast tumor cell lines were incubated in the presence or absence of roscovitine $(20 \mu \mathrm{M})$ and subsequently exposed to TRAIL $(500 \mathrm{ng} / \mathrm{ml})$ in the same culture media. Alternatively, the MDA-MB435-S and MCF-7 cells were treated with 25 and $50 \mathrm{ng} / \mathrm{ml}$ TRAIL, respectively. In all cell lines with the exception of MCF-7, apoptosis was measured as in (A). In MCF-7 cells apoptosis was determined by measuring PS externalization by flow cytometry as described in Materials and Methods.

Figure S1). MDA-MB231 cells only express TRAIL-R2 and R4 on the cell surface and, furthermore, the expression of these TRAIL receptors at the cell membrane was not significantly altered by exposure to roscovitine (Supple- mentary information, Figure S1). Hence, roscovitine does not appear to sensitize MDA-MB231 cells to TRAIL-induced apoptosis by modulating the surface expression of TRAIL receptors. 


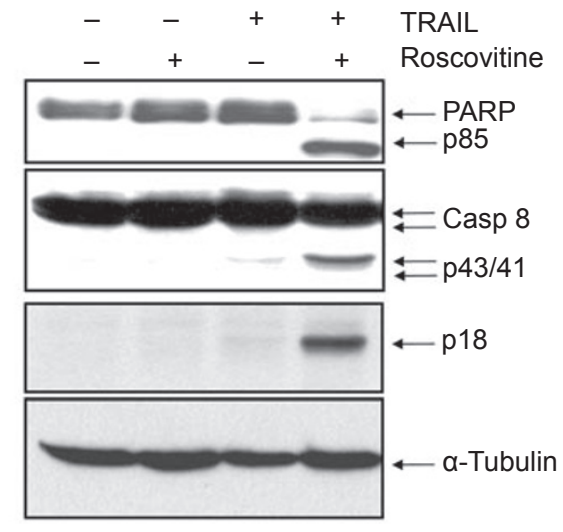

Figure 2 Roscovitine enhances the caspase- 8 activation and PARP cleavage induced by TRAIL without affecting the expression of TRAIL receptor at the cell membrane. MDA-MB231 cells were incubated with roscovitine $(20 \mu \mathrm{M})$ for $7 \mathrm{~h}$ prior to the addition of TRAIL (500 ng/ml) for $15 \mathrm{~h}$. Caspase-8 activation and PARP-1 cleavage were assessed by immunoblotting.

Recruitment of caspase- 8 and FADD to the TRAIL DISC is augmented in MDA-MB231 cells exposed to roscovitine

TRAIL binding to its receptors provokes the formation of the DISC, which contains FADD and caspase-8, the main proximal initiators of apoptosis. Therefore, roscovitine may render cells more susceptible to apoptosis by enhancing the formation of the TRAIL DISC. Using biotinylated TRAIL (TRAIL-b), we could monitor DISC formation by precipitating it from MDA-MB231 cell lysates with streptavidin-agarose beads. We found an increase in the recruitment of procaspase- 8 and FADD into the DISC of roscovitine-treated cells (Figure 3). Furthermore, there was an increase in the cleavage of procaspase- 8 to the p $43 / 41$ intermediate fragments and to the $\mathrm{p} 18$ subunit following exposure of the cells to roscovitine. The levels of $\mathrm{cFLIP}_{\mathrm{L}}$ and cFLIP $_{\mathrm{S}}$ recruited to the TRAIL DISC were slightly lower in the cells treated with roscovitine (Figure 3, compare lanes 3-4, 5-6 and 7-8). In addition, in both the control and pretreated cells, cFLIP ${ }_{\mathrm{L}}$ was cleaved by caspase- 8 to a $43 \mathrm{kDa}$ fragment $\left(\mathrm{FLIP}_{\mathrm{C}}\right)$, which probably represents the product obtained by removal of the $\mathrm{C}$-terminal $\mathrm{p} 10$ fragment. Thus, we observed an increase in the caspase-8/FLIP ratio in the DISC of roscovitine-treated cells, suggesting that this ratio may influence the sensitivity to TRAIL-induced apoptosis as indicated previously [32].

Roscovitine treatment induces the redistribution of TRAIL DISC components to lipid rafts and enhances the redistribution after TRAIL treatment

As we indicated previously, the induction of apoptosis by TRAIL can be regulated at different levels. Indeed, it was recently shown that lipid rafts may also be involved in signaling through TRAIL and other death receptors [33,

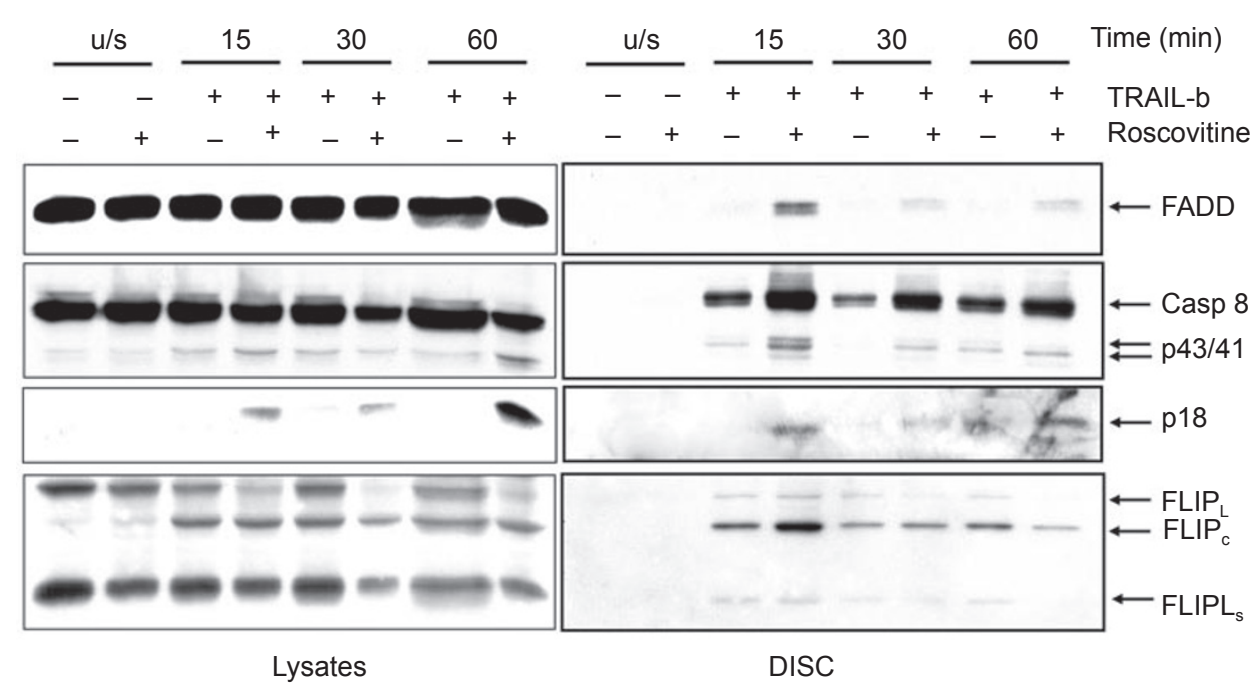

Figure 3 The recruitment of caspase 8 and FADD to the TRAIL DISC is enhanced after roscovitine treatment. MDA-MB231 cells incubated in the presence or absence of roscovitine $(20 \mu \mathrm{M}, 15 \mathrm{~h})$ were treated with biotinylated-TRAIL (TRAIL-b, $1 \mu \mathrm{g} / \mathrm{ml})$ for the times indicated. TRAIL receptor complexes were collected with streptavidin-conjugated agarose beads and analyzed by Western blotting for the TRAIL DISC components FADD, caspase-8, FLIP and FLIP . Unstimulated receptor controls $(u / s)$ represent the addition of biotinylated-TRAIL to an equivalent volume of lysate isolated from unstimulated cells. Lysates are included as a positive control for the expression of these proteins in MDA-MB231 cells. The data shown are representative of three independent experiments. 
34]. Accordingly, the redistribution of death receptors to lipid rafts facilitates the emission of signals that induce apoptosis. To determine whether lipid rafts are involved in the roscovitine sensitization to TRAIL apoptosis, MDA-MB231 cells were incubated with roscovitine for $15 \mathrm{~h}$, treated with TRAIL for $5 \mathrm{~min}$, and lipid rafts were then isolated by sucrose density gradient centrifugation as described in Materials and Methods (Figure 4A). Roscovitine treatment caused a redistribution of procaspase-8, FADD and TRAIL R2 to rafts (I fraction), and, although exposure to TRAIL alone also induced a redistribution of these proteins into rafts, pre-treatment with roscovitine enhanced this redistribution. However, the disruption of lipid rafts using methyl- $\beta$-cyclodextrin (MBCD) or Imipramine (Supplementary information, Figure S2), did not prevent the sensitization of tumor cells to TRAIL apoptosis promoted by roscovitine, suggesting that the localization to lipid rafts does not play a significant role in roscovitine sensitization.

Treatment with roscovitine impairs $c F L I P_{L}$ and $c F L I P_{S}$ $m R N A$ and protein expression

Several studies have suggested that a decrease in cFLIP, a short-lived protein, sensitizes cells to death receptor-induced apoptosis. Although this is somewhat controversial $[13,35]$, the antiapoptotic activity of this protein is clearly supported by data obtained from cells stably over-expressing cFLIP, from mice deficient in cFLIP and from the selective knockdown of cFLIP $[13,14]$.

When protein synthesis was inhibited in breast tumor cells with cycloheximide (CHX) before exposure to TRAIL (Figure 5A), all tumor cell lines tested were sensitized to the effects of TRAIL. Hence, short-lived inhibitory proteins

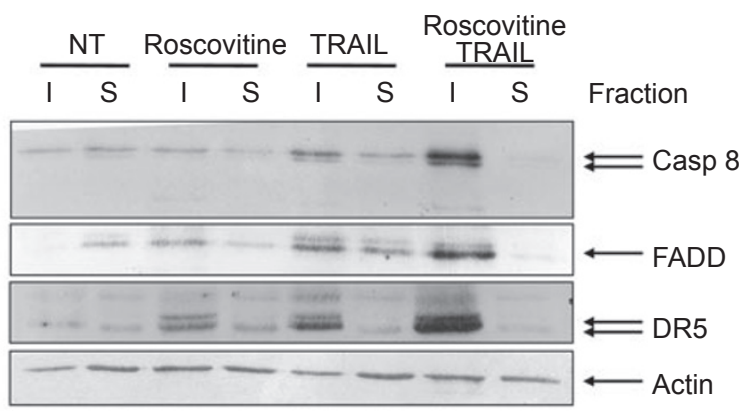

Figure 4 Roscovitine redistributes the TRAIL receptor-2 into lipid rafts. MDA-MB231 cells maintained in the presence or absence of roscovitine $(20 \mu \mathrm{M})$ for $15 \mathrm{~h}$ were stimulated with TRAIL-b (500 $\mathrm{ng} / \mathrm{ml}$ ) for $5 \mathrm{~min}$. The cells were then lysed in buffer containing $1 \%$ Triton; the detergent-soluble (S) and insoluble (I) fractions were isolated as described in Materials and Methods, and the expression of the indicated proteins was analyzed by western blotting. appear to play an important role in preventing TRAIL-induced apoptosis. Thus, we investigated whether roscovitine treatment affected the levels of $\mathrm{cFLIP}_{\mathrm{L}}$ and $\mathrm{cFLIP}_{\mathrm{S}}$ protein in MDA-MB231 cells. The protein levels of both $\mathrm{CFLIP}_{\mathrm{L}}$ and $\mathrm{cFLIP}_{\mathrm{S}}$ decreased in these cells following exposure to roscovitine (Figure 5B). The main decrease was found after $15 \mathrm{~h}$ of treatment and partial recovery of $\mathrm{cFLIP}_{\mathrm{L}}$ was observed after $24 \mathrm{~h}$ of treatment. To determine whether caspases were required for the roscovitine-mediated decrease in cFLIP expression, MDA-MB231 cells were treated with the pancaspase inhibitor benzyloxycarbonyl-Val-Ala-Asp(OMe) fluoromethyl ketone (z-VAD.FMK) for $1 \mathrm{~h}$ prior to the addition of roscovitine $(20 \mu \mathrm{M})$. Inhibition of caspase activity did not prevent the decline of either $\operatorname{cFLIP}_{\mathrm{L}}$ or cFLIP $_{s}$ levels upon roscovitine treatment, indicating that a caspase-independent mechanism was involved in reducing cFLIP expression (Figure 5C).

Post-translational regulation of cFLIP protein can occur through proteasome-mediated degradation $[17,24,36]$. Hence, we determined whether the reduction of cFLIP after roscovitine treatment was due to protein degradation through the proteasome machinery. In the presence of the proteasome inhibitors MG132 or epoxomicin, there was an increase in the accumulation of cFLIP protein (Figure 5D). Nevertheless, despite the inhibition of cFLIP degradation by the proteasome, roscovitine treatment still caused a decrease in the levels of cFLIP protein when compared with cells exposed to proteasome inhibitor alone, suggesting that roscovitine may down-regulate cFLIP at the mRNA level. Indeed, roscovitine diminishes the endogenous levels of cFLIP $_{\mathrm{L}}$ and $\mathrm{cFLIP}_{\mathrm{S}}$ mRNA in MDA-MB231 cells (Figure $5 \mathrm{E}$ and $5 \mathrm{~F}$ ). Moreover, there was a correlation between the cFLIP protein and mRNA levels following roscovitine treatment (Figure 5B and 5E) which suggests that roscovitine mainly down-regulates cFLIP at the mRNA level. However, we cannot completely exclude that treatment with roscovitine is also affecting cFLIP protein degradation by the ubiquitin/proteasome pathway.

Knockdown of endogenous $c F L I P_{L}$ and $c F L I P_{S}$ with siRNA oligonucleotides promotes apoptosis induced by TRAIL in breast tumor cells

Our data clearly show that roscovitine decreases cFLIP expression and sensitizes breast tumor cells to TRAILinduced apoptosis. Thus, we tested whether the specific silencing of cFLIP expression by siRNA has a similar effect on TRAIL-induced apoptosis. In MDA-MB231 cells, the levels of both cFLIP $_{\mathrm{L}}$ and $\mathrm{cFLIP}_{\mathrm{S}}$ were substantially reduced by a specific siRNA (Figure 6A), whereas a similar concentration of a scrambled control siRNA did not modify cFLIP protein expression. Transfection with cFLIP siRNA had no effect on the expression of procaspase-8, a struc- 


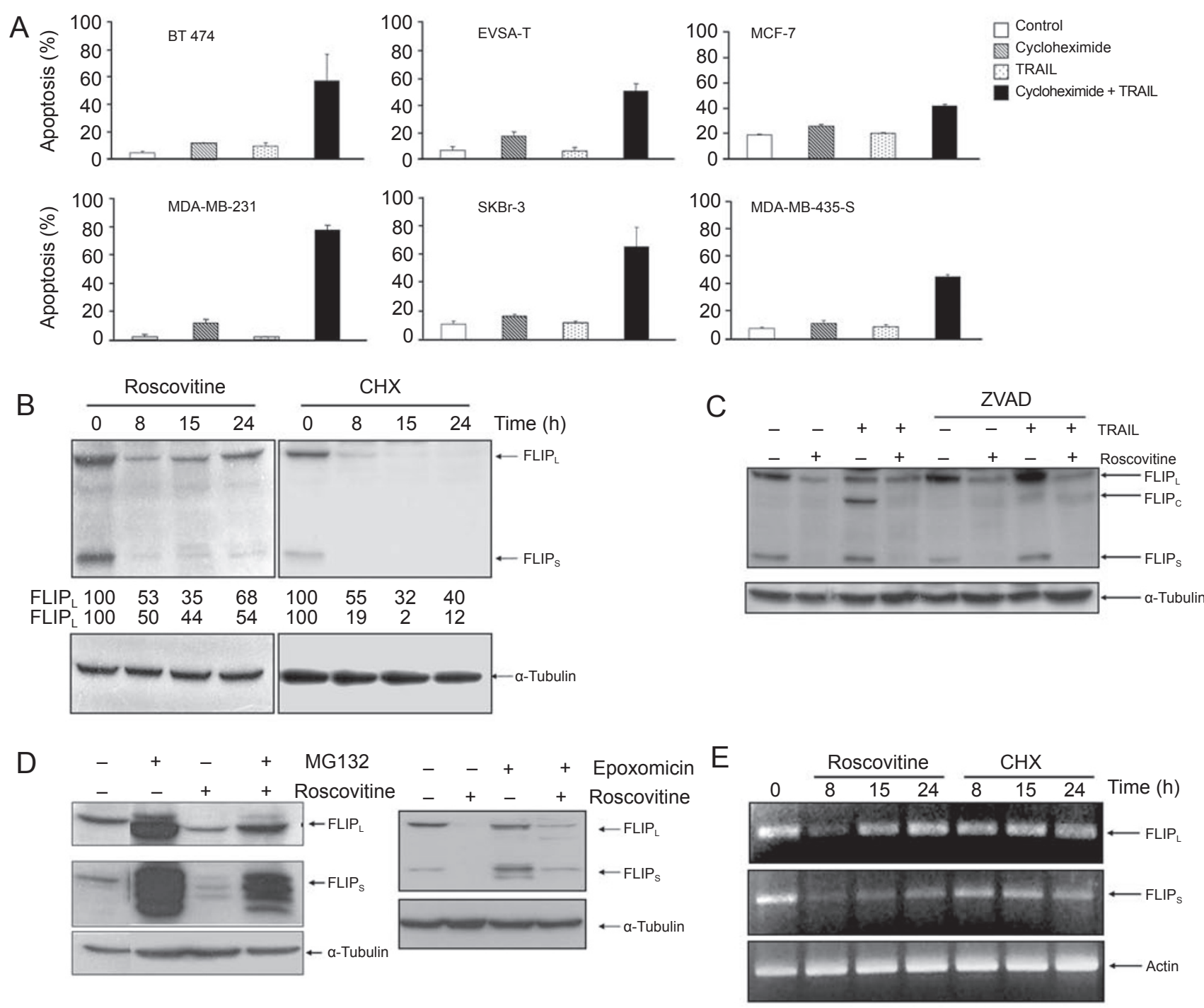

$\mathrm{F}$

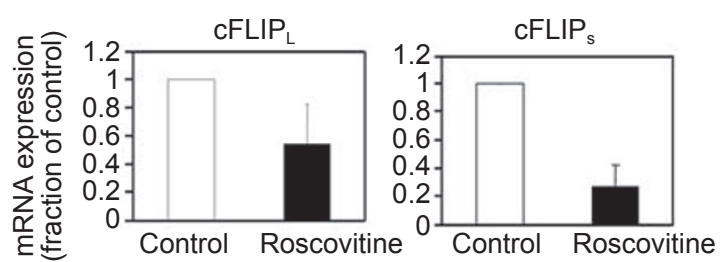

Figure 5 Exposure to roscovitine reduces cFLIP protein and mRNA levels. (A) Different breast tumor cell lines were incubated for $1 \mathrm{~h}$ in the presence or absence of cycloheximide $(\mathrm{CHX}, 5 \mu \mathrm{g} / \mathrm{ml})$ and then treated with TRAIL at $500 \mathrm{ng} / \mathrm{ml}(\mathrm{BT}-474$, SKBr3, EVSA-T, MDA-MB231), $50 \mathrm{ng} / \mathrm{ml}$ (MCF-7) or $25 \mathrm{ng} / \mathrm{ml}$ (MDA-MB435S), for a further $15 \mathrm{~h}$ period. Apoptosis was assessed as in Figure 1B. (B) Cells were incubated with roscovitine $(20 \mu \mathrm{M})$ or $\mathrm{CHX}(5 \mu \mathrm{g} / \mathrm{ml})$ for the times indicated. Levels of cFLIP protein were determined by western blotting as described in Materials and Methods. Densitometric analysis of cFLIP levels is presented as percentages of control (time 0 ), using tubulin levels as an internal control for normalization. (C) Cells were treated with roscovitine $(20 \mu \mathrm{M})$ for $15 \mathrm{~h}$, and then exposed to TRAIL $500 \mathrm{ng} / \mathrm{ml}$ for $7 \mathrm{~h}$ in the presence or absence of Z-VAD (50 $\mu \mathrm{M})$ added $1 \mathrm{~h}$ before TRAIL. The cells were then processed as in (A) to detect cFLIP protein levels. (D) MDA-MB231 cells were treated with roscovitine $(20 \mu \mathrm{M})$ for $24 \mathrm{~h}$ in the presence or absence of the proteasome inhibitors MG132 (25 $\mu \mathrm{M})$ or epoxomicin $(100 \mathrm{nM})$. Proteasome inhibitor was added $30 \mathrm{~min}$ before roscovitine and the CFLIP protein levels were analyzed by western blotting as in (A). (E) Cells were treated as in (B); the total RNA was isolated and CFLIP $\mathrm{L}_{\mathrm{L}}$ and $c F L I P_{S}$ mRNA transcripts were analyzed by RT-PCR as described in Materials and Methods. PCR amplification of $\beta$-actin was used as a control of the input RNA. (F) MDA-MB231 cells were treated with roscovitine $(20 \mu \mathrm{M})$ for $15 \mathrm{~h}$ and $\mathrm{CFLIP}$ and $\mathrm{cFLIP}$ SRNA levels were determined by real time RT-PCR as described in Materials and Methods. Results are the average and range of two independent experiments in triplicate. 
turally related proapoptotic protease (Figure 6A). Most importantly, silencing of cFLIP expression resulted in a clear sensitization to TRAIL-induced apoptosis (Figure $6 \mathrm{~B})$. These data correlated well with the effects of roscovitine and support the hypothesis that down-regulation of cFLIP expression by this CDK inhibitor is critical for the sensitization to TRAIL-induced apoptosis in breast tumor cells. To further substantiate the role of cFLIP in the sensitization observed, we generated MDA-MB231 cells over-expressing cFLIP $_{L}$ and determined the effect of roscovitine treatment on apoptosis by TRAIL. Results shown in Figure 6C demonstrate that cells over-expressing $\mathrm{cFLIP}_{\mathrm{L}}$ were clearly more resistant to roscovitine-induced

A

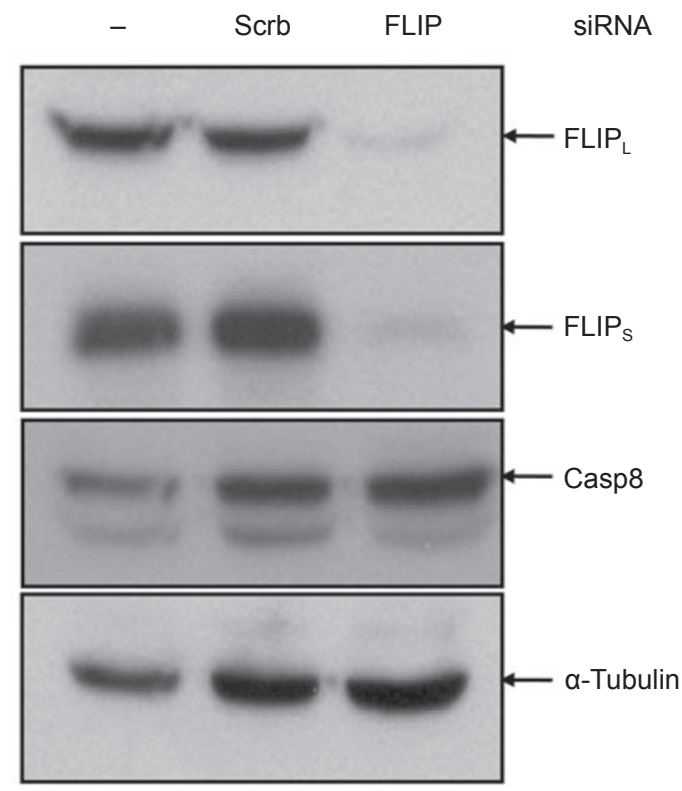

sensitization to TRAIL apoptosis than cells expressing normal cFLIP levels.

Down-regulation of antiapoptotic Mcl-1 protein expression by roscovitine contributes to sensitization to TRAILinduced apoptosis

Roscovitine alters the expression of different proteins involved in apoptosis $[6,28]$ and these modifications are associated with the induction of apoptosis by CDK inhibitors. On the other hand, it is known that the antiapoptotic Bcl-2 family member Mcl-1 protects cells from apoptosis and that it is up-regulated in different types of cancer [37, 38]. Furthermore, Mcl-1 down-regulation induces apoptosis

B
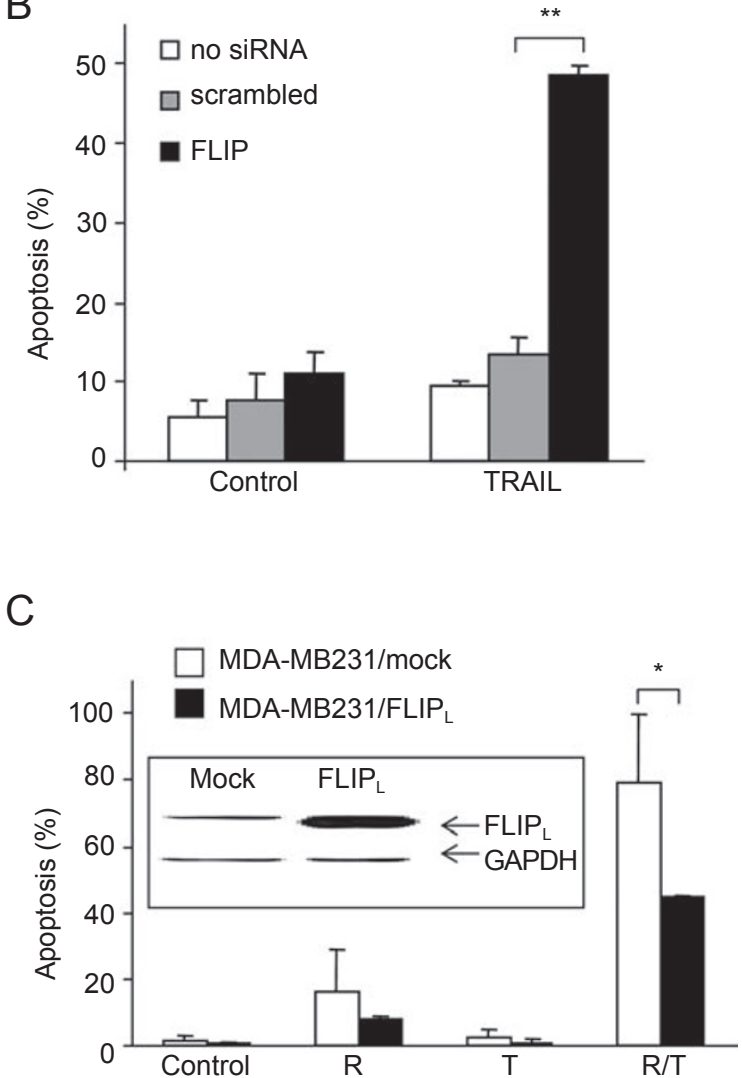

Figure 6 Knockdown of endogenous CFLIP and $C F L I P_{S}$ enhances the apoptosis induced by TRAIL in MDA-MB231 cells. (A) MDA-MB231 cells were transfected with either a siRNA oligonucleotide targeting both cFLIP isoforms, or a scrambled RNA oligonucleotide, as described in Materials and Methods. After $24 \mathrm{~h}$, the cells were harvested for immunoblot analysis to verify protein knockdown using Tubulin as a protein loading control. The results are representative of three independent experiments. (B) MDA-MB231 cells were transfected as in (A), and after $24 \mathrm{~h}$ TRAIL $(500 \mathrm{ng} / \mathrm{ml})$ was added to the cultures. Apoptosis was measured $24 \mathrm{~h}$ after the addition of TRAIL as described in Figure 1. Error bars represent S.D. from three independent experiments. ${ }^{* *} P<0.0001$. (C) Mock-transfected and MDA-MB231 cells transfected with the pCR3.V64-Met-Flag-FLIP $\mathrm{P}_{\mathrm{L}}$ vector were treated with roscovitine $(\mathrm{R})(20 \mu \mathrm{M})$ for $7 \mathrm{~h}$ prior to the addition of TRAIL $(\mathrm{T})(500 \mathrm{ng} / \mathrm{ml})$. Apoptosis was measured $15 \mathrm{~h}$ after the addition of TRAIL as the percentage of cells with sub-G1 DNA content, as described in Materials and Methods. The inset shows western blot analysis of FLIP $P_{L}$ expression in mock and FLIP $P_{L}$ transfected cells. GAPDH was used as an internal protein loading control. Error bars represent S.D. from three independent experiments. ${ }^{*} P<0.005$. 
[39] or sensitizes tumor cells to the apoptosis induced by different stimuli, including TRAIL [40-42]. Exposure to roscovitine markedly down-regulated Mcl-1 protein levels in MDA-MB231 cells (Figure 7A, top panel), suggesting that the decline in Mcl-1 may be a key event by which roscovitine sensitizes cells to TRAIL-induced apoptosis. In this respect, knockdown of Mcl-1 expression by siRNA (Figure 7A, bottom panels) significantly sensitized MDA-MB231 cells to TRAIL-induced apoptosis.

\section{E2F1 plays a significant role in roscovitine sensitization to TRAIL-induced apoptosis}

The transcription factor E2F1 is involved in the induction of apoptosis and its over-expression in various cell types sensitizes cells to apoptosis induced by ionizing radiation, chemotherapeutic drugs or death receptors [43, 44]. Here we show that roscovitine clearly up-regulates E2F1 protein levels (Figure 7B) in breast tumor cells. Interestingly, E2F1 has also been associated with the regulation of different apoptotic proteins including Mcl-1 and cFLIP $_{S}[44,45]$. By transfecting small specific interference RNAs, we disrupted E2F1 expression in MDA-MB231 cells to determine if the up-regulation of E2F1 induced by roscovitine affects
Mcl-1 and/or cFLIP expression. The transfected cells were exposed to roscovitine (for $15 \mathrm{~h}$ ) $24 \mathrm{~h}$ after siRNA transfection and the levels of the different apoptotic proteins were evaluated by immunoblotting. Knockdown of E2F1 did not alter the response of MDA-MB231 to roscovitine in terms of the expression of Mcl-1, cFLIP, XIAP, BID or Caspase-2 (Supplementary information, Figure S3), BAX and Apaf-1 (not shown) protein. However, although these protein levels remained unperturbed, there was a reversion of the roscovitine sensitization to TRAIL apoptosis when E2F1 was silenced (Figure 7C), demonstrating the importance of E2F1 in this sensitization process.

\section{Discussion}

Antitumor therapy based on the apoptosis-inducing properties of TRAIL and agonistic TRAIL receptor antibodies is currently under consideration [46]. However, despite the fact that TRAIL induces selective cell death in human tumor cells, sparing most untransformed cells, resistance to TRAIL is not uncommon in certain tumor cell lines. Furthermore, TRAIL might also promote cell migration and invasion in some apoptosis-resistant cells

A

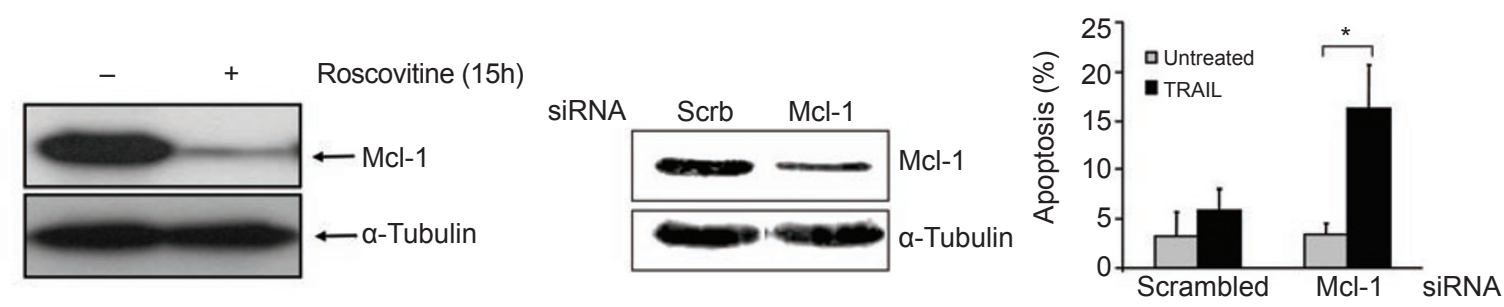

B
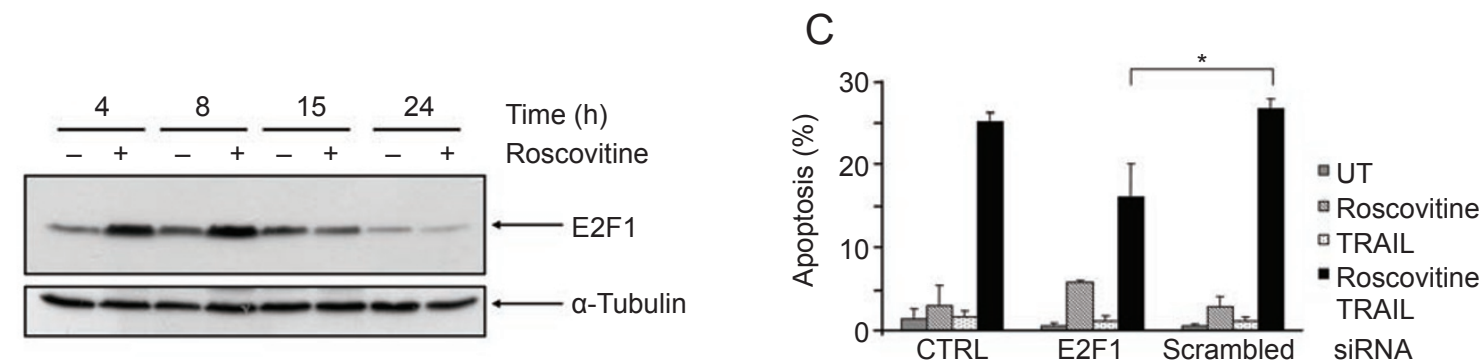

Figure 7 Down-regulation of Mcl-1 and up-regulation of E2F1 protein levels after roscovitine treatment in MDA-MB231 cells. MDA-MB231 cells were treated with roscovitine $(20 \mu \mathrm{M})$ for the times indicated and then Mcl-1 (A) or E2F1 (B) protein levels were analyzed by immunoblotting. The results are representative of at least three independent experiments. In $A$ (bottom panel, left) cells were transfected with either a siRNA oligonucleotide targeting Mcl-1, or a scrambled RNA oligonucleotide, as described in Materials and Methods. After $48 \mathrm{~h}$, the cells were collected and $\mathrm{Mcl}-1$ protein expression was analyzed by western blotting. In A (bottom panel, right) cells were siRNA transfected as in the left panel, and after $48 \mathrm{~h}$ TRAIL was added to the cultures. Apoptosis was measured $15 \mathrm{~h}$ after the addition of TRAIL as described in Figure 1. Error bars represent S.D. from three independent experiments. ${ }^{*} P<0.005$. (C) Cells were transfected and treated with roscovitine as in Supplementary information, Figure S3 following prior treatment with TRAIL for $2 \mathrm{~h}$. Apoptosis was determined as the percentage of subG1 cells. Error bars represent S.D. from three independent experiments. ${ }^{*} P<0.005$. 
[47]. Hence, sensitization of cells to TRAIL-induced apoptosis through different strategies would augment the therapeutic potential of TRAIL against its capacity to stimulate invasion, resolving the potential risk to patients with TRAIL-resistant cancers. Combination strategies have been implemented to facilitate TRAIL apoptotic signaling [48], and we have been investigating the resistance of human breast tumor cells to TRAIL and on how to overcome it. We previously indicated that the formation of the DISC is a common target for different sensitizing regimes [24, 49]. Indeed, CDK inhibitors have been reported to downregulate the expression of antiapoptotic proteins and to up-regulate the levels of pro-apoptotic regulatory proteins [24-27, 50]. The apoptosis-inducing potential of the CDK inhibitor roscovitine led us to investigate its effects on the resistance of breast tumor cells to TRAIL. We found that roscovitine sensitizes different breast tumor cell lines to TRAIL, including the highly resistant cell lines BT474 and $\mathrm{SkBr} 3$ that over-express the ErbB2 receptor. Indeed, roscovitine sensitizes breast tumor cell lines to TRAIL irrespective of their p53 status (see Table 1). While roscovitine did not alter surface expression of TRAIL receptors, the step(s) involved in the sensitization to TRAIL may reside downstream of ligand binding.

A DISC is formed upon TRAIL binding to its proapoptotic receptors [11]. In breast tumor cells treated with roscovitine, an increase in the recruitment of procaspase- 8 and FADD to the TRAIL DISC was observed, together with the complete activation of caspase- 8 . Whether or not roscovitine treatment induces post-translational modifications of FADD or TRAIL receptors that affect the binding affinities of the DISC components [51] remains to be ascertained. In this respect, it is noteworthy that treatments such as glucose deprivation, inhibition of CDKs and histone deacetylase (HDAC) inhibitors, all seem to enhance the formation of the TRAIL DISC in the absence of TRAIL receptor upregulation [24, 49, 52]. The localization of death receptors and other DISC components into lipid rafts may play a role in mediating sensitization to apoptotic stimuli $[33,53]$. Indeed, roscovitine itself caused a redistribution of DISC proteins into lipid rafts fractions and facilitated that induced by TRAIL in breast tumor cells. However, the disruption

Table 1 p53 status in breast tumor cell lines

\begin{tabular}{ll}
\hline & $\mathrm{p} 53$ \\
\hline MDA-MB231 & mutated \\
MCF-7 & normal \\
MDA-MB435-S & mutated \\
SKBr-3 & mutated \\
BT-474 & mutated \\
\hline
\end{tabular}

of either cholesterol or ceramide-enriched lipid rafts by specific inhibitors did not prevent roscovitine-induced sensitization to TRAIL in breast tumor cells. Hence, the redistribution of DISC components to membrane lipid rafts is not absolutely necessary to induce apoptosis by TRAIL in these cells. In this respect, the treatment of cells with MBCD failed to block CD95-mediated apoptosis in the Blymphoblastoid cell line SKW6.4 [35]. Furthermore, it has been demonstrated that acid sphingomyelinase-deficient hepatocytes and mice are protected from CD95-induced apoptosis or death. In contrast, acid sphingomyelinasedeficient and wild-type thymocytes, or Concanavalin- or lipopolysaccharide-pre-stimulated lymphocytes, were equally sensitive to CD95-induced apoptosis [54]. Together these results suggest that the requirement for death receptor localization in lipid rafts to activate apoptosis may be cell type dependent.

Since a protein synthesis inhibitor could restore the sensitivity of various breast tumor cell lines to TRAIL-induced apoptosis, short-lived inhibitory proteins are likely to be important to prevent TRAIL-induced signaling and apoptosis. We analyzed the expression of several antiapoptotic proteins such as cFLIP, Mcl-1 and XIAP, known to have a short half-life [55-57]. In cells treated with a sensitizing dose of roscovitine $\mathrm{cFLIP}_{\mathrm{L}}, \mathrm{cFLIP}_{\mathrm{S}}$ and Mcl-1 were markedly down-regulated. Moreover, the down-regulation of cFLIP protein was associated with a decrease in the mRNA levels for both $\mathrm{cFLIP}_{\mathrm{L}}$ and $\mathrm{CFLIP}_{\mathrm{S}}$ in cells treated with roscovitine. These results are in agreement with other data indicating that CDK inhibitors regulate transcription through the potent inhibition of positive transcription elongation factor $\mathrm{b}$ (P-TEFb), comprised of CDK9 and cyclin T1, thereby controlling the elongation phase of transcription by RNA polymerase II [58]. However, whereas flavopiridol has been shown to reduce global mRNA levels, at the doses used here roscovitine mostly affects a subset of cellular genes resulting in down-regulation of several short-lived proteins, including Mcl-1 [23, 59, 60]. In contrast, despite reports that roscovitine treatment down-regulates XIAP expression in glioma cells [6], we did not observe a decrease in XIAP protein levels in breast tumor cells treated with roscovitine. This is consistent with our previous results indicating that specific siRNA knockdown of XIAP did not sensitize breast tumor cells to TRAIL-induced apoptosis [24].

The importance of cFLIP down-regulation by roscovitine in the sensitization process was supported by the finding that siRNA silencing of cFLIP was sufficient to sensitize breast tumor cells to TRAIL-induced apoptosis. Competition between FADD and $\mathrm{CFLIP}_{\mathrm{L}}$ for the DD of TRAIL receptor DR5 [61] could also modulate DISC formation. The decrease in cFLIP $_{L}$ levels upon roscovitine treatment observed in our work could favor binding of FADD and pro- 
caspase- 8 to the TRAIL DISC. The increased recruitment of FADD and caspase- 8 to the TRAIL DISC observed in roscovitine-treated cells, together with a decrease in cFLIP levels, resulted in an elevation of the caspase-8/cFLIP ratio in the DISC of roscovitine-treated cells, which should facilitate caspase- 8 activation and promote apoptosis [32]. In breast tumor cells, TRAIL has been reported to induce apoptosis through a mitochondrial pathway, involving the translocation of truncated Bid and Bax to the mitochondria followed by the release of cytochrome $c$ from this organelle [62]. The anti-apoptotic Bcl-2 family member Mcl-1 has recently been reported to bind truncated Bid and to prevent death-receptor mediated apoptosis [40, 63]. Furthermore, Mcl-1 down-regulation by siRNA has also been demonstrated to restore the sensitivity of tumor cells to TRAIL-induced apoptosis [26]. Our results also demonstrate that silencing of Mcl-1 expression by siRNA partly sensitizes breast tumor cells to TRAIL-induced apoptosis. Based on these evidence, it seems very likely that Mcl-1 down-regulation upon exposure to roscovitine could cooperate with cFLIP depletion to facilitate TRAILinduced release of apoptotic factors from the mitochondria in breast tumor cells.

Our data show that treatment with a sensitizing dose of roscovitine caused a marked increase in E2F1 protein expression in breast tumor cells. The role played by E2F1 in the sensitization process was evaluated by siRNA silencing, indicating that the knockdown of E2F1 expression significantly reduced roscovitine-induced sensitization to TRAIL. A previous report has demonstrated that over-expression of E2F1 in human lung adenocarcinoma cell lines caused the down-regulation of cFLIPs expression and sensitized these cells to death receptor-induced apoptosis [44]. Furthermore, E2F1 directly represses Mcl-1 expression by binding to the Mcl-1 gene promoter. Together, these data suggest that the roscovitine-induced depletion of both cFLIP and Mcl-1 in breast tumor cells may be mediated by E2F1 up-regulation. However, we failed to observe reversal of cFLIP and Mcl1 down-regulation in cells that were depleted of E2F1 by siRNA silencing. Clustering of the death receptor CD95/Fas and formation of the DISC in the absence of ligand have been also reported in cells over-expressing E2F1 [44]. Whether the increased recruitment of procaspase- 8 and FADD to the TRAIL DISC observed in roscovitine-treated breast tumor cells is mediated by up-regulation of E2F1 is an issue that requires further study.

In conclusion, roscovitine can induce apoptosis in different tumor cell lines and causes regression of human xenograft tumors in mice [20]. Since it also seems less toxic for normal cells than other CDK inhibitors [28], it might be a good candidate to use in combined strategies against breast cancer. In fact, treatment with CDK inhibitors sensitizes tumor cells to apoptosis induced by different anti-tumor agents $[64,65]$. In the present study, we show that roscovitine treatment sensitizes human breast tumor cell lines to TRAIL-induced apoptosis, independent of the p53 and ErbB-2 receptor status, through a pleiotropic mechanism that involves increased DISC formation, cFLIP and Mcl1 down-regulation, and E2F1 up-regulation. The present findings provide further support for the general strategy of combining TRAIL and CDK inhibitors in anti-cancer regimens against TRAIL-resistant tumor cells.

\section{Materials and Methods}

\section{Reagents and antibodies}

Roscovitine, MBCD, Imipramine, streptavidin-agarose beads, and MG 132 were obtained from SIGMA Chemical Corp. (St Louis, MO). Soluble human His-tagged recombinant TRAIL and biotin-labeled recombinant TRAIL (bTRAIL) were generated in our laboratory as described [66]. Anti-human TRAIL-receptor R1, R2, R3 and R4 antibodies and anti-cFLIP monoclonal antibody (NF6) were from Alexis Corp. (San Diego, CA). Anti-caspase 8 was a gift from Dr Gerald Cohen (Leicester University, UK). Bax, XIAP FADD and RIP antibodies were from BD Bioscience (Erembodegem, Belgium). The PARP polyclonal antiserum was from Roche Molecular Biochemicals (Germany). The monoclonal antibody to alpha-tubulin was purchased from Sigma Chemical Corp. Antibodies against GAPDH, Mcl-1 (S19), E2F1 (KH95), DR5 (N19) and Caspase-2-L were from Santa Cruz Biotechnology, Inc (Santa Cruz, CA). Horseradish peroxidase or FITC conjugated, goat anti-mouse and goat anti-rabbit secondary antibodies were obtained from DAKO (Cambridge, UK). zVAD-fmk was from Bachem AG (Bachem, Bubendorf, Switzerland).

\section{Cell culture}

The human tumor cell lines MDA-MB231 and EVSA-T were maintained in RPMI 1640 medium supplemented with $10 \%$ fetal bovine serum, $2 \mathrm{mM}$ L-glutamine, and $40 \mu \mathrm{g} / \mathrm{ml}$ gentamycin. MDAMB468, SKBr-3, MDA-MB435-S and BT-474 were maintained in Dulbecco's modified Eagle's medium (DMEM) supplemented with $10 \%$ fetal bovine serum, $2 \mathrm{mM}$ L-glutamine, and $40 \mu \mathrm{g} / \mathrm{ml}$ gentamycin. MDA-MB435-S was also supplemented with insulin $(10 \mu \mathrm{g} / \mathrm{ml})$. The cells were maintained at $37^{\circ} \mathrm{C}$ in a humidified $5 \%$ $\mathrm{CO}_{2}, 95 \%$ air incubator. A stable cell line over-expressing $\mathrm{cFLIP}_{\mathrm{L}}$ was generated upon transfection of MDA-MB231 cells with pCR3. V64-Met-Flag-FLIP $_{\mathrm{L}}$ (a kind donation of Dr J Tschopp, University of Lausanne) by electroporation. Mock-transfected cells and cells over-expressing FLIP $_{\mathrm{L}}$ were selected in culture medium with $1 \mathrm{mg} /$

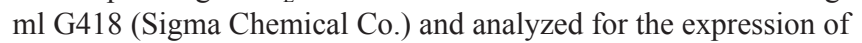
cFLIP $_{\mathrm{L}}$ by Western blot.

\section{Analysis of apoptosis}

Hypodiploid apoptotic cells were detected by flow cytometry according to published procedures [10]. Phosphatidylserine (PS) exposure on the surface of apoptotic cells was detected by flow cytometry after staining with Anexin-V-FLUOS (Roche Molecular Biochemicals).

\section{Immunoblot analysis of proteins}

The assay for measurements of cytochrome $c$ and Bax was 
performed as described previously [49]. Proteins were resolved on SDS-polyacrylamide minigels and visualized as described previously [10].

\section{Analysis of TRAIL receptors by flow cytometry}

MDA-MB231 cells were detached with RPMI 1640/EDTA, washed in ice-cold PBS, and resuspended in PBS. Cells were then labeled with anti-TRAIL receptor antibodies $(5 \mu \mathrm{g} / \mathrm{ml})$ or no antibody (negative control), and then incubated with goat anti-mouse FITCconjugated antibody $\mathrm{F}\left(\mathrm{ab}^{\prime}\right)_{2}$ fragment. Labeled cells were analyzed by flow cytometry using the CellQuest software (Becton Dickinson, Mountain View, CA).

\section{Isolation of the TRAIL DISC}

DISC precipitation was performed using biotin-tagged recombinant TRAIL (bio-TRAIL) [66]. MDA-MB231 cells were incubated for $15 \mathrm{~h}$ in the presence or absence of $20 \mu \mathrm{mol} / 1$ roscovitine and they were then exposed to bio-TRAIL for the times indicated in Figure 3. DISC formation was determined as reported previously [66].

\section{Reverse transcriptase (RT) and PCR assays}

Total RNA was isolated from MDA-MB231 cells with the Trizol reagent (Life Technologies, Inc., Grand Island, NY) as recommended by the supplier. Total RNA $(2 \mu \mathrm{g})$ was used as a template for cDNA synthesis using a RT-PCR kit (Perkin-Elmer). PCRs were carried out using specific primers for $\mathrm{cFLIP}_{\mathrm{L}}$ and $\mathrm{cFLIP}_{\mathrm{S}}$ as described previously [24].

\section{Real-time RT-PCR}

MDA-MB231 cells were treated with roscovitine $(20 \mu \mathrm{M})$ for 15 h. Total RNA was isolated from cells as described before. Total RNA $(1 \mu \mathrm{g})$ was used as a template for cDNA synthesis using a RT-PCR kit (Perkin-Elmer) with the supplied random hexamers and under the conditions described by the manufacturer. mRNA expression was analyzed in triplicate by quantitative RT-PCR on the ABI Prism 7500 sequence detection system using predesigned Assay-on-demand primers and probes (Applied Biosystems). mRNA expression was determined by the comparative cycle threshold $(\mathrm{Ct})$ method $\left(\Delta \Delta C_{\mathrm{t}}\right)$. Hypoxanthine-guanine phosphoribosyltransferase was used as an internal control and mRNA expression levels of $\mathrm{cFLIP}_{\mathrm{L}}$ and $\mathrm{cFLIP}_{\mathrm{S}}$ were given as fraction of mRNA levels in control cells.

\section{TRAIL stimulation and isolation of lipid rafts}

Sixty million cells were left untreated or stimulated for the indicated time points with $1 \mu \mathrm{g} / \mathrm{ml}$ TRAIL-biotinylated after pre-incubation with Roscovitine $(20 \mu \mathrm{M}, 15 \mathrm{~h})$ where indicated. Treated samples were routinely collected to subsequently evaluate cell viability as described [67]. Lipid raft extraction was performed according to standard protocols [68]. Briefly, the cell pellet was dissolved in $750 \mu \mathrm{l}$ of $1 \%$ Triton $\mathrm{X}-100 / 25 \mathrm{mM} \mathrm{MES} / 150 \mathrm{mM} \mathrm{NaCl}$ buffer at $4{ }^{\circ} \mathrm{C}$. After homogenization, the cell lysates were subjected to sucrose gradient centrifugation at $45000 \mathrm{rpm}$ for $16 \mathrm{~h}$ in an SW60 rotor (Beckman Instruments). Twelve $375-\mu 1$ fractions were collected from the top to the bottom of each gradient. For cholesterol depletion studies, cells were treated with $10 \mathrm{mM} \mathrm{MBCD}$ for $30 \mathrm{~min}$ at $37^{\circ} \mathrm{C}$ in serum-free medium before lipid raft isolation.

\section{Statistical analysis}

All data are presented as the mean \pm SE of at least three in- dependent experiments. The differences among different groups were determined by the Student's $t$ test. $P<0.05$ was considered significant.

\section{References}

1 Ashkenazi A, Dixit VM. Death receptors: signaling and modulation. Science 1998; 281:1305-1308.

2 Sheridan JP, Marsters SA, Pitti RM, et al. Control of TRAILinduced apoptosis by a family of signaling and decoy receptors. Science 1997; 277:818-821.

3 Ashkenazi A, Pai RC, Fong S, et al. Safety and antitumor activity of recombinant soluble Apo2 ligand. J Clin Invest 1999; 104:155-162.

4 Reed JC. Drug insight: cancer therapy strategies based on restoration of endogenous cell death mechanisms. Nat Clin Pract Oncol 2006; 3:388-398.

5 El-Zawahry A, McKillop J, Voelkel-Johnson C. Doxorubicin increases the effectiveness of Apo2L/TRAIL for tumor growth inhibition of prostate cancer xenografts. BMC Cancer 2005; 7:2-5.

6 Kim EH, Kim SU, Shin DY, Choi KS. Roscovitine sensitizes glioma cells to TRAIL-mediated apoptosis by downregulation of survivin and XIAP. Oncogene 2004; 23:446-456.

7 Lashinger LM, Zhu K, Williams SA, Shrader M, Dinney CP, McConkey DJ. Bortezomib abolishes tumor necrosis factor-related apoptosis-inducing ligand resistance via a p21-dependent mechanism in human bladder and prostate cancer cells. Cancer Res 2005; 65:4902-4908.

8 Chinnaiyan AM, Prasad U, Shankar S, et al. Combined effect of tumor necrosis factor-related apoptosis-inducing ligand and ionizing radiation in breast cancer therapy. Proc Natl Acad Sci USA 2000; 97:1754-1759.

9 Ohtsuka T, Buchsbaum D, Oliver P, Makhija S, Kimberly R, Zhou T. Synergistic induction of tumor cell apoptosis by death receptor antibody and chemotherapy agent through $\mathrm{JNK} / \mathrm{p} 38$ and mitochondrial death pathway. Oncogene 2003; 22:2034-2044.

10 Ruiz-Ruiz C, Lopez-Rivas A. Mitochondria-dependent and -independent mechanisms in tumour necrosis factor-related apoptosis-inducing ligand (TRAIL)-induced apoptosis are both regulated by interferon-gamma in human breast tumour cells. Biochem J 2002; 365:825-832.

11 Sprick MR, Weigand MA, Rieser E, et al. FADD/MORT1 and caspase- 8 are recruited to TRAIL receptors 1 and 2 and are essential for apoptosis mediated by TRAIL receptor 2. Immunity 2000; 12:599-609.

12 Irmler M, Thome M, Hahne M, et al. Inhibition of death receptor signals by cellular FLIP. Nature 1997; 388:190-195.

13 Krueger A, Schmitz I, Baumann S, Krammer PH, Kirchhoff S. Cellular FLICE-inhibitory protein splice variants inhibit different steps of caspase-8 activation at the CD95 death-inducing signaling complex. J Biol Chem 2001; 276:20633-20640.

14 Sharp DA, Lawrence DA, Ashkenazi A. Selective knockdown of the long variant of cellular FLICE inhibitory protein augments death receptor-mediated caspase- 8 activation and apoptosis. $J$ Biol Chem 2005; 280:19401-19409.

15 Yeh WC, Itie A, Elia AJ, et al. Requirement for Casper (c-FLIP) in regulation of death receptor-induced apoptosis and embryonic development. Immunity 2000; 12:633-642. 
16 Kreuz S, Siegmund D, Scheurich P, Wajant H. NF-кB inducers upregulate cFLIP, a cycloheximide-sensitive inhibitor of death receptor signaling. Mol Cell Biol 2001; 21:3964-3973.

17 Fukazawa T, Fujiwara T, Uno F, et al. Accelerated degradation of cellular FLIP protein through the ubiquitin-proteasome pathway in p53-mediated apoptosis of human cancer cells. Oncogene 2001; 20:5225-5231.

18 Grana X, Reddy EP. Cell cycle control in mammalian cells: role of cyclins, cyclin dependent kinases (CDKs), growth suppressor genes and cyclin-dependent kinase inhibitors (CKIs). Oncogene 1995; 11:211-219.

19 Meijer L, Borgne A, Mulner O, et al. Biochemical and cellular effects of roscovitine, a potent and selective inhibitor of the cyclin-dependent kinases cdc2, cdk2 and cdk5. Eur J Biochem 1997; 243:527-536.

20 McClue SJ, Blake D, Clarke R, et al. In vitro and in vivo antitumor properties of the cyclin dependent kinase inhibitor CYC202 (R-roscovitine). Int J Cancer 2002; 102:463-468.

21 Whittaker SR, Walton MI, Garrett MD, Workman P. The Cyclindependent kinase inhibitor CYC202 (R-roscovitine) inhibits retinoblastoma protein phosphorylation, causes loss of Cyclin D1, and activates the mitogen-activated protein kinase pathway. Cancer Res 2004; 64:262-272.

22 Mgbonyebi OP, Russo J, Russo IH. Roscovitine induces cell death and morphological changes indicative of apoptosis in MDA-MB231 breast cancer cells. Cancer Res 1999; 59:1903-1910.

23 MacCallum DE, Melville J, Frame S, et al. Seliciclib (CYC202, R-Roscovitine) induces cell death in multiple myeloma cells by inhibition of RNA polymerase II-dependent transcription and down-regulation of Mcl-1. Cancer Res 2005; 65:5399-5407.

24 Palacios C, Yerbes R, Lopez-Rivas A. Flavopiridol induces cellular FLICE-inhibitory protein degradation by the proteasome and promotes TRAIL-induced early signaling and apoptosis in breast tumor cells. Cancer Res 2006; 66:8858-8869.

25 Rosato RR, Dai Y, Almenara JA, Maggio SC, Grant S. Potent antileukemic interactions between flavopiridol and TRAIL/Apo2L involve flavopiridol-mediated XIAP downregulation. Leukemia 2004; 18:1780-1788.

26 Taniai M, Grambihler A, Higuchi H, et al. Mcl-1 mediates tumor necrosis factor-related apoptosis-inducing ligand resistance in human cholangiocarcinoma cells. Cancer Res 2004; 64:35173524.

27 Ma Y, Cress WD, Haura EB. Flavopiridol-induced apoptosis is mediated through up-regulation of E2F1 and repression of Mcl-1. Mol Cancer Ther 2003; 2:73-81.

28 Hahntow IN, Schneller F, Oelsner M, et al. Cyclin-dependent kinase inhibitor Roscovitine induces apoptosis in chronic lymphocytic leukemia cells. Leukemia 2004; 18:747-755.

29 Bodmer JL, Holler N, Reynard S, et al. TRAIL receptor-2 signals apoptosis through FADD and caspase-8. Nat Cell Biol 2000; 2:241-243.

30 Kischkel FC, Lawrence DA, Chuntharapai A, Schow P, Kim KJ, Ashkenazi A. Apo2L/TRAIL-dependent recruitment of endogenous FADD and caspase- 8 to death receptors 4 and 5. Immunity 2000; 12:611-620.

31 Gibson SB, Oyer R, Spalding AC, Anderson SM, Johnson GL. Increased expression of death receptors 4 and 5 synergizes the apoptosis response to combined treatment with etoposide and TRAIL. Mol Cell Biol 2000; 20:205-212.
32 MacFarlane M, Harper N, Snowden RT, et al. Mechanisms of resistance to TRAIL-induced apoptosis in primary B cell chronic lymphocytic leukaemia. Oncogene 2002; 21:6809-6818.

33 Delmas D, Rebe C, Micheau O, et al. Redistribution of CD95, DR4 and DR5 in rafts accounts for the synergistic toxicity of resveratrol and death receptor ligands in colon carcinoma cells. Oncogene 2004; 23:8979-8986.

34 Vanoosten RL, Moore JM, Ludwig AT, Griffith TS. Depsipeptide (FR901228) enhances the cytotoxic activity of TRAIL by redistributing TRAIL receptor to membrane lipid rafts. Mol Ther 2005; 11:542-552.

35 Chang DW, Xing Z, Pan Y, et al. c-FLIP(L) is a dual function regulator for caspase-8 activation and CD95-mediated apoptosis. EMBO J 2002; 21:3704-3714.

36 Kim Y, Suh N, Sporn M, Reed JC. An inducible pathway for degradation of FLIP protein sensitizes tumor cells to TRAILinduced apoptosis. J Biol Chem 2002; 277:22320-22329.

37 Michels J, O’Neill JW, Dallman CL, et al. Mcl-1 is required for Akata6 B-lymphoma cell survival and is converted to a cell death molecule by efficient caspase-mediated cleavage. Oncogene 2004; 23:4818-4827.

38 Zhou P, Levy NB, Xie H, et al. MCL1 transgenic mice exhibit a high incidence of B-cell lymphoma manifested as a spectrum of histologic subtypes. Blood 2001; 97:3902-3909.

39 Zhang B, Gojo I, Fenton RG. Myeloid cell factor-1 is a critical survival factor for multiple myeloma. Blood 2002; 99:18851893.

40 Clohessy JG, Zhuang J, de Boer J, Gil-Gomez G, Brady HJ. Mcl-1 interacts with truncated Bid and inhibits its induction of cytochrome c release and its role in receptor-mediated apoptosis. J Biol Chem 2006; 281:5750-5759.

41 Han J, Goldstein LA, Gastman BR, Rabinowich H. Interrelated roles for Mcl-1 and BIM in regulation of TRAIL-mediated mitochondrial apoptosis. J Biol Chem 2006; 281:10153-10163.

42 Wirth T, Kuhnel F, Fleischmann-Mundt B, et al. Telomerasedependent virotherapy overcomes resistance of hepatocellular carcinomas against chemotherapy and tumor necrosis factor-related apoptosis-inducing ligand by elimination of Mcl-1. Cancer Res 2005; 65:7393-7402.

43 Nip J, Strom DK, Fee BE, Zambetti G, Cleveland JL, Hiebert SW. E2F-1 cooperates with topoisomerase II inhibition and DNA damage to selectively augment p53-independent apoptosis. Mol Cell Biol 1997; 17:1049-1056.

44 Salon C, Eymin B, Micheau O, et al. E2F1 induces apoptosis and sensitizes human lung adenocarcinoma cells to death-receptor-mediated apoptosis through specific downregulation of c-FLIP(short). Cell Death Differ 2006; 13:260-272.

45 Croxton R, Ma Y, Song L, Haura EB, Cress WD. Direct repression of the Mcl-1 promoter by E2F1. Oncogene 2002; 21:13591369.

46 Fesik SW. Promoting apoptosis as a strategy for cancer drug discovery. Nat Rev Cancer 2005; 5:876-885.

47 Trauzold A, Siegmund D, Schniewind B, et al. TRAIL promotes metastasis of human pancreatic ductal adenocarcinoma. Oncogene 2006; 25:7434-7439.

48 Held J, Schulze-Osthoff K. Potential and caveats of TRAIL in cancer therapy. Drug Resist Updat 2001; 4:243-252.

49 Munoz-Pinedo C, Ruiz-Ruiz C, Ruiz de Almodovar C, Palacios C, Lopez-Rivas A. Inhibition of glucose metabolism sensitizes 
tumor cells to death receptor-triggered apoptosis through enhancement of death-inducing signaling complex formation and apical procaspase-8 processing. J Biol Chem 2003; 278:1275912768.

50 Mihara M, Shintani S, Kiyota A, Matsumura T, Wong DT. Cyclindependent kinase inhibitor (roscovitine) suppresses growth and induces apoptosis by regulating Bcl-x in head and neck squamous cell carcinoma cells. Int J Oncol 2002; 21:95-101.

51 Harper N, Hughes MA, Farrow SN, Cohen GM, MacFarlane M. Protein kinase $\mathrm{C}$ modulates tumor necrosis factor-related apoptosis-inducing ligand-induced apoptosis by targeting the apical events of death receptor signaling. J Biol Chem 2003; 278:44338-44347.

52 Inoue S, MacFarlane M, Harper N, Wheat LM, Dyer MJ, Cohen GM. Histone deacetylase inhibitors potentiate TNF-related apoptosis-inducing ligand (TRAIL)-induced apoptosis in lymphoid malignancies. Cell Death Differ 2004; 11(Suppl 2):S193-206.

53 Gajate C, Mollinedo F. Edelfosine and perifosine induce selective apoptosis in multiple myeloma by recruitment of death receptors and downstream signaling molecules into lipid rafts. Blood 2007; 109:711-719.

54 Lin T, Genestier L, Pinkoski MJ, et al. Role of acidic sphingomyelinase in Fas/CD95-mediated cell death. J Biol Chem 2000; 275:8657-8663.

55 Nijhawan D, Fang M, Traer E, et al. Elimination of Mcl-1 is required for the initiation of apoptosis following ultraviolet irradiation. Genes Dev 2003; 17:1475-1486.

56 Poukkula M, Kaunisto A, Hietakangas V, et al. Rapid turnover of c-FLIPshort is determined by its unique C-terminal tail. J Biol Chem 2005; 280:27345-27355.

57 Yang Y, Fang S, Jensen JP, Weissman AM, Ashwell JD. Ubiquitin protein ligase activity of IAPs and their degradation in proteasomes in response to apoptotic stimuli. Science 2000; 288:874-877.

58 Chao SH, Price DH. Flavopiridol inactivates P-TEFb and blocks most RNA polymerase II transcription in vivo. J Biol Chem 2001; 276:31793-31799.

59 Lam LT, Pickeral OK, Peng AC, et al. Genomic-scale mea- surement of mRNA turnover and the mechanisms of action of the anti-cancer drug flavopiridol. Genome Biol 2001; 2: RESEARCH0041.

60 Alvi AJ, Austen B, Weston VJ, et al. A novel CDK inhibitor, CYC202 (R-roscovitine), overcomes the defect in p53-dependent apoptosis in B-CLL by down-regulation of genes involved in transcription regulation and survival. Blood 2005; 105:44844491.

61 Jin TG, Kurakin A, Benhaga N, et al. Fas-associated protein with death domain (FADD)-independent recruitment of c-FLIPL to death receptor 5. J Biol Chem 2004; 279:55594-55601.

62 Ruiz de Almodovar C, Ruiz-Ruiz C, Munoz-Pinedo C, Robledo G, Lopez-Rivas A. The differential sensitivity of Bc1-2-overexpressing human breast tumor cells to TRAIL or doxorubicin-induced apoptosis is dependent on $\mathrm{Bc1}-2$ protein levels. Oncogene 2001; 20:7128-7133.

63 Certo M, Del Gaizo Moore V, et al. Mitochondria primed by death signals determine cellular addiction to antiapoptotic BCL-2 family members. Cancer Cell 2006; 9:351-365.

64 Dai Y, Grant S. Cyclin-dependent kinase inhibitors. Curr Opin Pharmacol 2003; 3:362-370.

65 Edamatsu H, Gau CL, Nemoto T, Guo L, Tamanoi F. Cdk inhibitors, roscovitine and olomoucine, synergize with farnesyltransferase inhibitor (FTI) to induce efficient apoptosis of human cancer cell lines. Oncogene 2000; 19:3059-3068.

66 Harper N, Farrow SN, Kaptein A, Cohen GM, MacFarlane M. Modulation of tumor necrosis factor apoptosis-inducing ligandinduced NF- $\kappa$ B activation by inhibition of apical caspases. $J$ Biol Chem 2001; 276:34743-34752.

67 De Maria R, Lenti L, Malisan F, et al. Requirement for GD3 ganglioside in CD95- and ceramide-induced apoptosis. Science 1997; 277:1652-1655.

68 Parolini I, Sargiacomo M, Lisanti MP, Peschle C. Signal transduction and glycophosphatidylinositol-linked proteins (lyn, lck, CD4, CD45, G proteins, and CD55) selectively localize in Tritoninsoluble plasma membrane domains of human leukemic cell lines and normal granulocytes. Blood 1996; 87:3783-3794.

(Supplementary Information is linked to the online version of the paper on the Cell Research website) 